http://jmscr.igmpublication.org/home/

ISSN (e)-2347-176x ISSN (p) 2455-0450

crossref DOI: https://dx.doi.org/10.18535/jmscr/v10i1.26

Journal Of Medical Science And Clinical Research

IGM Publication

An Official Publication of IGM Publication

\title{
Missing Intra-Uterine Device for Contraception in a Referral Health Institution in a Less Developed Country: Are We Safe
}

\author{
Authors \\ Oranu Okwudili Emmanuel*, Inya Ngalagu John \\ Dept of Obstetrics and Gynaecology, Fertility Regulation and Reproductive Unit \\ University of Port Harcourt Teaching Hospital, Port Harcourt, Nigeria \\ *Corresponding Author \\ Oranu Emmanuel
}

\begin{abstract}
Background: Intra-uterine device (IUD) for contraception is a modern long acting reversible contraceptive. Though it is one of the commonly used contraceptives generally, it is not without its problems. It could sometimes be "missing"(missing IUD), hence this study.

Objectives: To determine the prevalence and management of missing IUD at the University of Port Harcourt Teaching Hospital (UPTH), Port Harcourt.

Materials and Methods: The study was a 10 year review of hospital records of all women with missing IUD, who visited the family planning clinic of the University of Port Harcourt Teaching Hospital from January $1^{\text {st }} 2007$ to December $31^{\text {st }}$ 2016. Data was analyzed using version 23.0 of the Statistical Package for Social Sciences (SPSS) statistical software. Descriptive statistics was conducted and summarized as means and standard deviations for continuous variables, and as frequencies and percentages for categorical variables.

Results: Of the 25,014 clients who presented for contraceptive at the family planning clinic of the UPTH during the study period, 5054 (20.2\%) used IUD. Of the IUD users, only 25(0.49\%) had missed IUD. Insertion was done in tertiary care centre in $92 \%$ of the clients with missing IUD. All the clients who had missing IUD presented with missing string, were diagnosed clinically and alligator forceps used for retrieval. None of the clients with missing IUD had any complications from its management.

Conclusion: The prevalence of missing IUD for contraception in the UPTH is $0.49 \%$. The diagnosis of this condition is clinical and its retrieval simple and safe. This suggests that the insertion of IUDs done by skilled personals is safer and management of the missing cases less likely to be complicated.

Keywords: Intrauterine device for contraception, missing, UPTH, Port Harcourt, Nigeria.
\end{abstract}

\section{Introduction}

Intra uterine device (IUD) for contraception is a modern long acting reversible contraceptive. ${ }^{1}$ It has existed for centuries, and historians attributed its origin to the Arabs who stuck pebbles into the uteri of their camels to prevent them from getting pregnant on long trips across the desert. ${ }^{2}$ It has undergone several modifications from the old inert devices such as lippes loop, to the modern devices that has either copper or levonorgestrel attached to their frame. ${ }^{3,2}$ It now comes in different shapes and sizes with improved efficacy and reduced side effect, and also with increased rate of acceptance and prolonged usage period. ${ }^{2}$

It is the second most popularly used contraceptive method worldwide after the mini pill, and the commonest contraceptive in Nigeria and other developing countries because of its efficiency, 
affordability and availability. ${ }^{1,2}$ Approximately 128 million women are using it all over the world. ${ }^{1}$ In Nigeria, available studies put IUD users in the range of 47 to $66 \%$ of contraceptive acceptors in different family planning centers. ${ }^{2}$ In the University of Port Harcourt teaching hospital, it is responsible for $16.2 \%$ of contraceptive use. ${ }^{2}$

Though IUD is one of the most commonly used reversible method of birth control/limiting worldwide, it is not without side effects. ${ }^{4}$ These include pelvic inflammatory disease, increased risk of ectopic pregnancy as well as accidental pregnancy, other are expulsion, coital difficulties, menstrual abnormalities and transmigration leading to a missing IUD and very occasionally, uterine perforations. These accounts for the associated high discontinuation rates of about 20$40 \% .^{5}$

Missing IUD strings occur in 5-25\% of all insertions and require a safe and correct diagnostic technique. ${ }^{1}$ A missing IUD string does not necessarily indicate perforation since it may occur when the device has been expelled unnoticed, rotation of the device within the uterine cavity, enlargement of the uterus by pregnancy, separation of the tail from the device, insertion into one horn of a uterine didelphys or retraction of the string into the cervical canal. ${ }^{1}$

The risk factors for missing IUD include the time of its insertion, type, size and configuration of the IUD. ${ }^{1}$ In most cases, there are no associated symptoms and the diagnosis of displaced IUD is made when the string of the device cannot be identified. Copper T380A has been the major intrauterine device offered to clients in our family planning unit.

Cases of missing IUD have not been evaluated since the inception of this method in this unit more a decade ago, hence this study to provide data on the prevalence and management of missing IUD in the UPTH.

\section{Materials and Methods}

The study was a 10 year review of hospital records of all women with missing intrauterine device for contraceptive, who visited the family planning clinic of the University of Port Harcourt Teaching Hospital from January $1^{\text {st }} 2007$ to December $31^{\text {st }}$ 2016. The IUD used in all the clients was CU T 380A. The Folder numbers of all the patients who have been on intra uterine contraceptive device during the study period were retrieved. These numbers were used to retrieve the cases notes of the clients, and the data extracted include the socio-demographic data, the type of IUD used, the timing of insertion, the presenting complains, the method of diagnosis and retrieval methods.

Information obtained from the records was analyzed using version 23.0 of the Statistical Package for Social Sciences (SPSS) statistical software. Descriptive statistics was conducted and summarized as means and standard deviations for continuous variables, and as frequencies and percentages for categorical variables. Data was presented on frequency distribution tables.

\section{Results}

\section{Socio-demographic Characteristics}

A total number of 25,014 clients presented for contraceptive at the family planning clinic of the University of Port Harcourt Teaching Hospital during the study period. The IUD users, accounted for $5054(20.2 \%)$ of the total number. Of these IUD users, twenty five cases of missing IUD for contraception were diagnosed and managed giving an incidence of $0.49 \%$. All the missing IUD were $\mathrm{Cu} \mathrm{T}$ 380A. The age of clients diagnosed with missing IUD ranged from 27 to 57 years, majority (68.0\%) were between 30-39 years, the mean age was 37.8 years and the standard deviation was 6.84 years. Nineteen $(76.0 \%)$ of them had $1-4$ children while $6(24.0 \%)$ had five or more children. The mean parity was $3 \pm 1.12$, and all the clients were married. Most $(72.0 \%)$ of women with missing IUD had tertiary education. Their occupational status were mainly private sector employee (44.0\%) and civil servant (24.0\%). See table 1 below. 
Table 1: Socio-demographic characteristics of clients with missing IUCD

\begin{tabular}{lcc}
\hline Variable & Frequency $(\mathbf{n = 2 5})$ & Percentage \\
\cline { 1 - 3 } Age (years) & 1 & \\
$<30$ & 17 & 4.0 \\
$30-39$ & 5 & 68.0 \\
$40-49$ & 2 & 20.0 \\
$\geq 50$ & $37.80 \pm 6.84$ & 8.0 \\
Meanage \pm SD (years) & & \\
Parity & 19 & 76.0 \\
$1-4$ & 6 & 24.0 \\
$\geq 5$ & & \\
Level of Education & 7 & 28.0 \\
Secondary & 18 & 72.0 \\
Tertiary & & \\
Occupation & 3 & 12.0 \\
House wife & 5 & 20.0 \\
Public servant & 11 & 44.0 \\
Private sector & 6 & 24.0 \\
Civil servant & & \\
\hline
\end{tabular}

\section{BMI Status}

Twenty one $(84.0 \%)$ of the clients with missing IUCD were at least overweight. The mean BMI was $29.83 \pm 5.78 \mathrm{Kg} / \mathrm{m}^{2}$. See table 2 below.

Table 2: BMI Status of clients with missing IUCD

\begin{tabular}{lcc}
\hline Variable & $\begin{array}{c}\text { Frequency } \\
(\mathbf{n = 2 5})\end{array}$ & Percentage \\
\hline BMI Status $\left(\mathbf{K g} / \mathbf{m}^{\mathbf{2}}\right)$ & & \\
Underweight $(<18.5)$ & 0 & 0.0 \\
Normal weight $(18.5-24.9)$ & 4 & 16.0 \\
Overweight $(25.0-29.9)$ & 10 & 40.0 \\
Obese $(\geq 30)$ & 11 & 44.0 \\
Mean weight \pm SD $(\mathbf{K g})$ & $79.8 \pm 15.4$ & \\
Mean height \pm SD $(\mathbf{m})$ & $1.64 \pm 0.025$ & \\
Mean BMI $\pm \mathbf{S D}\left(\mathbf{K g} / \mathbf{m}^{\mathbf{2}}\right)$ & $29.83 \pm 5.78$ & \\
\hline
\end{tabular}

\section{Clinical presentation, diagnosis and management of IUD}

Fourteen $(56.0 \%)$ of the clients with missing IUD had not used any contraceptive previously, 2 (8.0\%) had used natural method and $6(24.0 \%)$ had used condom. Eighteen $(72 \%)$ of the clients had used IUD for less than five years, while 7 $(28 \%)$ of them used it for five years or more. IUD was inserted in tertiary care in $92 \%$ of the clients with missing IUD. The time of insertion of IUD was during post menstruation in all the clients, presenting complain was missing string in all the clients and diagnosis of missing IUD was made clinically in all the clients while alligator forceps was used for their retrieval. None of the clients with missing IUD presented with any complications after retrieval. See table 3 below.
Table 3: Clinical presentation, diagnosis and management of IUD

\begin{tabular}{|c|c|c|}
\hline Variable & $\begin{array}{l}\text { Frequency } \\
(\mathbf{n}=25)\end{array}$ & Percentage \\
\hline \multicolumn{3}{|l|}{ Previous use of contraceptive } \\
\hline None & 14 & 56.0 \\
\hline Natural method & 2 & 8.0 \\
\hline Condom & 6 & 24.0 \\
\hline Injectable & 1 & 4.0 \\
\hline Others & 2 & 8.0 \\
\hline \multicolumn{3}{|l|}{ Duration of IUD use (years) } \\
\hline$<5$ & 18 & 72.0 \\
\hline$\geq 5$ & 7 & 28.0 \\
\hline \multicolumn{3}{|l|}{ Where IUD was inserted } \\
\hline Primary care & 1 & 4.0 \\
\hline Secondary care & 1 & 4.0 \\
\hline Tertiary care & 23 & 92.0 \\
\hline \multicolumn{3}{|l|}{ Time of IUD insertion } \\
\hline Post menstruation & 25 & 100.0 \\
\hline \multicolumn{3}{|l|}{ Presenting complain } \\
\hline Missing string & 25 & 100.0 \\
\hline \multicolumn{3}{|l|}{ Diagnosis of missing IUD } \\
\hline Abdomino-pelvic ultrascan & 25 & 100.0 \\
\hline $\begin{array}{l}\text { Method } \\
\text { management/retrival of }\end{array}$ & & \\
\hline Alligator forcep & 25 & 100.0 \\
\hline \multicolumn{3}{|l|}{ Location of missing IUD } \\
\hline Uterine cavity & 25 & 100.0 \\
\hline \multicolumn{3}{|l|}{ Complications of IUD } \\
\hline No complication & 25 & 100.0 \\
\hline
\end{tabular}

\section{Discussion}

The combination of efficacy and long acting reversible nature of the IUD makes it a choice contraception for many women seeking protection against pregnancy. The prevalence of IUD among women who used contraceptives in this centre was $20.2 \%$. This value was higher than the finding of a Nigerian study conducted in Abakiliki in SouthEast Nigeria, which reported a prevalence of $13.2 \%,{ }^{3}$ but lower than the finding of another Nigeria study conducted in Nnewi in Southern Nigeria, which reported a prevalence of 50.9\%. ${ }^{6}$ In the Abakiliki study, the respondents were poorly educated, and hence had poor knowledge of contraception in general and the use of IUD in particular. $^{3}$

Reports from different family planning units in Nigeria, has shown the prevalence rate of IUD for contraception to be between 35 and $66 \% .^{7}$ This relatively high prevalence is because this method is not coitus dependent, is cost effective and long acting. $^{7}$ Intrauterine device for contraception usage among women ranges from $16.2 \%$ to $64.1 \%{ }^{1,-3,6,8-10}$ Globally, IUD is the second most 
popular contraceptive and the most popular contraceptive in sub-saharan Africa and most parts of Nigeria. ${ }^{1,4,7}$

The prevalence of missing IUD for contraception in the study period was $0.45 \%$ which is higher than $0.08 \%$ reported in a Nigerian study conducted among women who attended the Family Planning Clinic of the University of Nigeria Teaching Hospital in Enugu ${ }^{1}$, but far less than $16.7 \%$ and $3.6 \%$ recorded in Abakiliki and Nnewi respectively ${ }^{3,11}$

Most of the clients with missing IUD were between 30 and 39 years, with the age averaging to 37 years. This age could likely be linked to the fact that most of the clients were carrier women with tertiary level of education who did not want their obstetric carrier to interfere with their jobs. Most of clients had tertiary level of education. This could be attributed to the fact that the study was done in a tertiary centre, and that most of the clients attending the family planning clinic in this centre were linked directly or indirectly to the tertiary institution (for example, place of work and proximity to place of residence which is urban). Also, over two-third of the clients with missing IUD were multiparous, and this conformed to reports of studies done in Abakaliki, Nnewi, and Calabar. $^{3,11,12}$ This is not surprising as several studies have shown that majority of IUD acceptors were multiparous. This is possibly because, most of these women are done with child bearing and wanted methods that will serve as a limiter instead of spacing. This further exposes multiparous clients to the complications which occur due to this method of contraceptive. ${ }^{2,3,12}$. The observation in this study that most of the clients with missing IUD were overweight supports the study which showed that overweight women were more likely to use long acting reversible contraceptive such as IUD. ${ }^{13}$

In this study, over $90 \%$ of the clients with missing IUD presented with history of inability to feel the IUD thread, while $4 \%$, presented with a history of complete expulsion of the IUD; all the missing IUD were copper T380A. More than half (56\%) of the clients with missing IUD had not used any other form of contraceptive before this experience. A higher percentage of clients with missing IUD, who had not used any other form of contraceptive, were also observed in the study conducted among women in Enugu. ${ }^{1}$ This would mostly likely serve as perceived barrier to further use of contraceptives, hence, adequate pre-insertion counseling is advocated. However, about threequarter of the women with missing IUD had been on IUD for five years or less, that IUD was done in a tertiary care in about $92 \%$ of cases with missing IUD, and that insertion was done in the post-menstruation. This apparently showed that protocols were strictly adhered to in the insertion processes of the IUDs.

All the clients were diagnosis of missing IUD had abdomino-pelvic ultrasound scan. This method of diagnosis, though readily available, is not reliable when the missing IUD is covered by omentum. ${ }^{1,14}$ This technique was different from that used in the studies conducted in Abakaliki, Calabar and Enugu where the diagnosis of missing IUD were mostly confirmed by a plain abdominal $\mathrm{X}$ ray. ${ }^{1,3}$ Other methods of confirming the diagnosis of missing IUD include; hysteroscopy which is of great value not only for precise locating of the IUD but also for its removal under direct vision, particularly in the management of patients with broken and or embedded IUD ${ }^{1}$. However, in instances where the missing IUD has perforated the uterus and is lodged in the abdominal cavity, hysteroscopy becomes less useful. Other diagnostic techniques available include; hysterosalpingogram (HSG) which is an invasive procedure, sonogram in cases where IUD is surrounded by the omentum and loops of bowel, CT scan when missing IUD has migrated outside the uterine cavity, cystoscopy which helps diagnose intravesical IUD and MRI when required. ${ }^{13,14}$ These methods, though more precise than abdomino pelvic ultra sound scan, are not usually cost effective. ${ }^{1,4,16-18}$

The study also noted that missing IUD occurred in the uterine cavity in all the clients with missing 
IUD studied. This agrees with the findings in Ife which suggested that a clinical diagnosis of missing IUD can be made after radiological investigations such as ultrasonography, plain $\mathrm{x}$ rays and computerized tomography. ${ }^{15}$

Retrieval of IUD was done in all clients with missing IUD using the hook retrieval method or the Alligator forceps. Alligator forceps were commonly used for retrieval of IUD in clients without complications; and this is the case in almost all of our clients with missing IUD. Other methods of management depend on the location of the IUD. This includes dilatation and retrieval, the use of a tracer IUD and exploratory laparotomy when the device is lodged in the abdominal cavity. However, when available, laparoscopy is preferred to laparotomy, since it is less traumatic and carries less post-operative morbidity. There were no complications associated with IUD retrieval in all the clients with missing IUD in this study. However, IUD method of contraception is associated with other complications. These complications include painful abdominal cramps, expulsion, complete or partial uterine perforation, menstrual disturbance, increased risk of ectopic, pregnancy, PID and device migration.

\section{Conclusion}

The prevalence of missing intrauterine device for contraception in UPTH is very low. The diagnosis of this condition in our centre is mainly clinical and its retrieval simple and safe. This suggests that the insertion of IUDs done by skilled personnel is safer and the management of any possible missing cases, less likely to be complicated.

Ethical Consideration: Not Applicable.

Conflict of Interest: There was no conflict of interest between authors

\section{References}

1. Ezegwui HU, Ikeako LC, Egbuji C. Missing Intrauterine Contraceptive Device amongst Clients in Enugu, Nigeria. Niger J Surg. 2011; 17(2):60-63.
2. Enyindah CE, Ojule JD, Bassey G. Contraception with Intrauterine Contraceptive Device (IUCD) in Port Harcourt, South-South Nigeria. J Med Biomed Res. 2012;11(1):35-45

3. Igwe. Intrauterine contraceptive device use in Abakaliki, southeast Nigeria: A 5-year review 2016;19(2);138-143

4. Jimoh AA, Balogun OR. Missing IUD strings: diagnosis and management at Illorin. Niger J Med 2004; 13(2):118-123

5. Moitra B, Bhagat M. A case report of successful retrieval of missing $\mathrm{Cu} \mathrm{T}$ from peritoneal cavity in a case of pelvic Tuberculosis. Int $\mathbf{J}$ Reprod Contracept Obstet Gynecol. 2017;6(11):5152-51548.

6. Dinwoke. Intrauterine contraceptive device acceptors in Nnamdi Azikiwe University Teaching Hospital, Nnewi, Southeastern Nigeria - A 5-year review2015;18;(2);6873.

7. Alagbe OA, Oyekale OI, Bello AB, Akinyoade ON. Case report: Intravesical Migration of Intrauterine Contraceptive Device In A Nigerian Woman, A Case Report. West Afr J Ultrasound 2017;18(2).178-180

8. Taingson MC, Adze JA, Bature SB, Durosinlorun AM, Caleb M, Amina A, et al. Trend of modern contraceptive uptake and its predictors among women accessing family planning service in a tertiary hospital in Northwestern Nigeria, 20002014. Trop J Obstet Gynaecol. 2017;34(3):201-206.

9. Dimkpa OJ, Oranu OE, Wamadi NE. Intrauterine contraceptive device use in Port Harcourt, Southern Nigeria: a retrospective analysis. Br J Med Med Res. 2014;4(16):3132-9.

10. Ishaku S, Onwe S, Gaji L. Determinants of mordern contraceptive use among married female undergraduate at the Ahmadu Bello University, Zaria in Nigeria 2017;4 (7):170-176 
11. Joseph I, Daniel O. Missing IUD String: Prevalence, diagnosis and retrieval in Nnewi, Nigeria 2009;18(3):303-305

12. Iklaki CU, Agbakwuru AU, Udo AE, Abeshi SE. Five-year review of copper T intrauterine device use at the University of Calabar Teaching Hospital, Calabar. Open Access J Contracept. 2015;( 5);6:143-147.

13. Bhuva K, Kraschnewski JL, Lehman EB, Chuang $\mathrm{CH}$. Does body mass index or weight perception affect contraceptive use? Contraception. 2017;95(1):59-64.

14. Goswami D, Ravi AK, Sharma A. Missing IUD Strings: Role of Imaging in Locating the Misplaced Device. J Clin Diagn Res JCDR. 2017;11(4):1-2.

15. Ibitoye BO, Aremu AA, Onuwaje MA, Ayoola OO. What is the fate of the missing intrauterine contraceptive device? Trop Doct. $2009 ; 39(4): 221-223$.

16. Igwegbe AO, Ugboaja JO, Monago EN. A ten year clinical experience with intrauterine contraceptive device (IUCD) in Nigerian tertiary health institution. Int $\mathbf{J}$ Med Sci 2010;2:347-353.

17. Zakin D, Stern WZ, Rosenblatt R. Complete and partial uterine perforation and embedding following insertion of intrauterine devices: Diagnostic method, prevention and management. Obstet Gynecol Surv 1987;36:401-417

18. Deshmukh S, Ghanouni P, Jeffrey RD. Early sonographic diagnosis of intrauterine device migration to the adnexae. J Clin Ultrasound 2009;37(7):414-416. 